\title{
Direct Catalytic Route to Biomass-Derived 2,5-Furandicarboxylic Acid and Its Use as Monomer in a Multicomponent Polymerization
}

\author{
Oliver R. Schade, ${ }^{\dagger \neq}$ Patrick-Kurt Dannecker, ${ }^{\S}$ Kai F. Kalz, ${ }^{\dagger, \ddagger}$ David Steinbach, ${ }^{\ddagger}, \|$ \\ Michael A. R. Meier, ${ }^{*}, \S_{0}$ and Jan-Dierk Grunwaldt*, $\dagger, \neq$ (1) \\ $\dagger$ Institute for Chemical Technology and Polymer Chemistry (ITCP), Karlsruhe Institute of Technology (KIT), Engesserstr. 20,
76131 Karlsruhe, Germany
${ }^{\ddagger}$ Institute of Catalysis Research and Technology (IKFT), KIT, Hermann-von-Helmholtz-Platz 1, 76344 Eggenstein-Leopoldshafen,
Germany
${ }^{\S}$ Institute for Organic Chemistry (IOC), KIT, Straße am Forum 7, 76131 Karlsruhe, Germany
"Institute of Agricultural Engineering, Conversion Technologies of Biobased Resources, University of Hohenheim, Garbenstraße 9,
70599 Stuttgart, Germany
}

Supporting Information

ABSTRACT: Efficient synthesis of valuable platform chemicals from renewable feedstock is a challenging, yet essential strategy for developing technologies that are both economical and sustainable. In the present study, we investigated the synthesis of 2,5-furandicarboxylic acid (FDCA) in a two-step catalytic process starting from sucrose as largely available biomass feedstock. In the first step, 5-(hydroxymethyl)furfural (HMF) was synthesized by hydrolysis and dehydration of sucrose using sulfuric acid in a continuous reactor in $34 \%$ yield. In a second step, the resulting reaction solution was directly oxidized to FDCA without further purification over a $\mathrm{Au} / \mathrm{ZrO}_{2}$ catalyst with $84 \%$ yield ( $87 \%$ selectivity, batch process), corresponding to $29 \%$ overall yield with respect to sucrose. This two-step process could afford the production of pure FDCA after the respective extraction/crystallization despite the impure

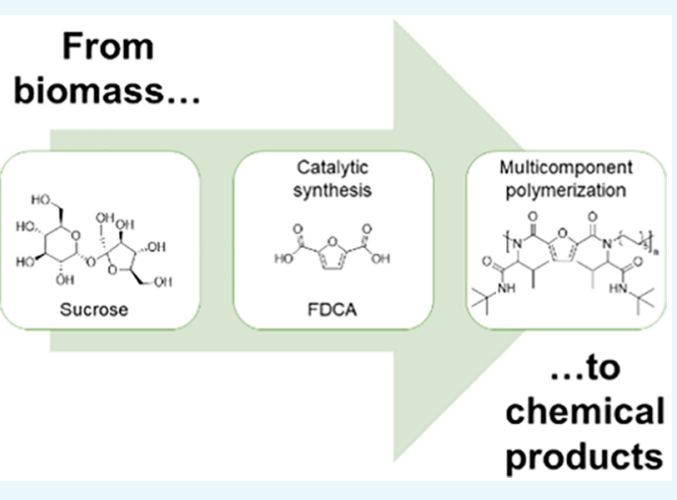
intermediate HMF solution. To demonstrate the direct application of the biomass-derived FDCA as monomer, the isolated product was used for Ugi-multicomponent polymerizations, establishing a new application possibility for FDCA. In the future, this efficient two-step process strategy toward FDCA should be extended to further renewable feedstock.

\section{INTRODUCTION}

Diminishing fossil resources in combination with an increasing demand for chemical products necessitate the exploitation of sustainable feedstock. ${ }^{1-4}$ Hence, the use of biomass as a renewable carbon source for the production of chemicals represents a very active field of research. ${ }^{3,5,6}$ The partial decomposition of biomass leads to so-called platform molecules that are suitable for subsequent conversion into valuable products. One of the often considered versatile platform molecules is 5-(hydroxymethyl)furfural (HMF).,7 HMF can be produced from hexoses and their polymers ${ }^{8}$ via acid-catalyzed dehydration in numerous solvents ranging from aqueous, organic to biphasic solvent systems using both homogeneous and heterogeneous catalysts. ${ }^{6,9}$ Dehydration of hexoses in water using mineral acid catalysts is a promising approach for HMF production because water is potentially a green solvent and both the solvent and the catalysts are relatively cheap. ${ }^{10}$ Several strategies already reported on the further conversion of HMF to valuable products include hydrogenation, ${ }^{11}$ dehydrogenation, ${ }^{12}$ or hydrodeoxygenation. ${ }^{13,14}$ One of the most promising products obtained by the selective oxidation of HMF is 2,5-furandicarboxylic acid (FDCA), which is an alternative to fossil-based monomers in future plastics, such as poly(ethylene furanoate). ${ }^{15-18} \mathrm{HMF}$ can be oxidized using bio- ${ }^{19,20}$ or electrocatalysts ${ }^{21,22}$ as well as homogeneous $^{23,24}$ and heterogeneous metal catalysts. ${ }^{18,25,26}$ Especially the heterogeneously catalyzed oxidation of HMF with oxygen or air in water has gained increasing interest in the last years due to substantial advantages, e.g., catalyst recovery and recyclability, as well as due to sustainability considerations. Among others, gold catalysts have been proven to be highly active in FDCA synthesis. ${ }^{27-32}$ However, when biomass or carbohydrates are used as feedstock for the synthesis of HMF, impurities like humins are generated, lowering the catalytic activity of further conversions. ${ }^{33,34}$ Therefore, most studies on FDCA synthesis report on the use of pure HMF. This is far from efficient or sustainable because purification of HMF is cost- and resource-intensive. Thus, the synthesis of FDCA

Received: July 28, 2019

Accepted: August 19, 2019

Published: October 1, 2019 
starting from biomass remains challenging. Only a few studies were published for the synthesis of FDCA starting from mixtures directly produced from biomass or carbohydrate hydrolysis. ${ }^{25,26}$ A loss of catalytic activity of the oxidation catalyst resulting from contact with impurities can be circumvented by spatial separation of the dehydration from the oxidation reaction, either by using multiphase reactions ${ }^{35,36}$ or by two-step processes. $33,37-44$

In addition to its use as a substitute for terephthalic acid, FDCA may also be used as a monomer for other novel polymers. In this respect, we investigated isocyanide-based multicomponent reactions (MCRs), among which the Passerini three-component reaction ${ }^{45}$ and Ugi four-component reaction (Ugi-4CR) ${ }^{46,47}$ are particularly interesting in polymer science due to their versatility. ${ }^{48-53}$ For instance, the direct synthesis of polyamides ${ }^{54}$ and polyesteramides ${ }^{55}$ was achieved via the Ugi reaction. More recently, isocyanide-based MCRs were used for a variety of applications in polymer science ranging from monomer synthesis ${ }^{56-60}$ to postpolymerization modification. ${ }^{56,61-64}$

In an ideal case of FDCA synthesis, the HMF obtained by biomass hydrolysis should be directly oxidized and only then FDCA is purified in the last step before polymerization. In the present study, the whole process chain starting from sucrose hydrolysis and subsequent dehydration to HMF and the final oxidation and polymerization steps have been examined and are depicted in Scheme 1. Notably, sucrose is a relatively cheap

Scheme 1. Schematic Two-Step Reaction to FDCA Starting from Sucrose and Its Use as Monomer for the UgiMulticomponent Polymerization

$$
\text { catalytic synthesis }
$$

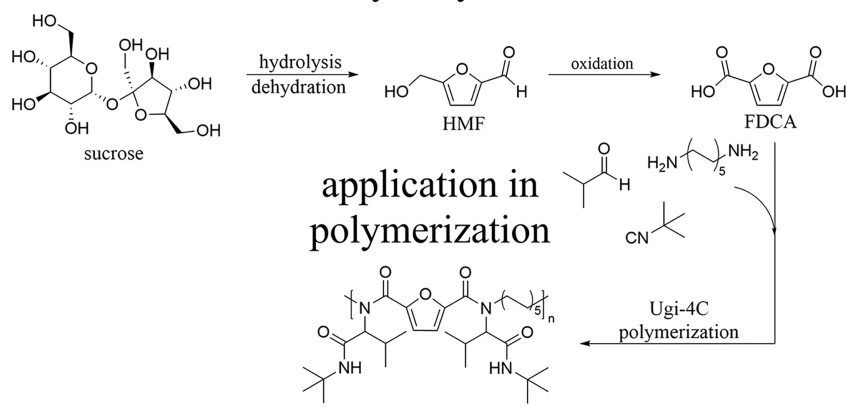

and widely available feedstock, also allowing the simulation of a reaction solution obtained from cellulosic biomass with subsequent isomerization of glucose. Therefore, this model feedstock can be substituted at a later stage by cellulose or hemicellulose. In the next step, unpurified HMF was directly oxidized with air over a $1.6 \mathrm{wt} \% \mathrm{Au} / \mathrm{ZrO}_{2}$ catalyst without any purification, but adjustment of $\mathrm{pH}$. Finally, FDCA was extracted, crystallized with sufficient purity, and used as monomer for a multicomponent Ugi-4CR polymerization, a novel application for FDCA.

\section{RESULTS AND DISCUSSION}

2.1. Catalytic Synthesis of FDCA. The choice of the feedstock is an essential aspect considering the scale as well as the efficiency of processes based on renewable resources. In the present study, HMF was produced from sucrose in a continuous tubular reactor with sulfuric acid as the catalyst for hydrolysis as well as dehydration. ${ }^{10}$ Glucose, fructose, xylose, furfural, levulinic acid, formic acid, and uncharacterized polymeric products were the main residues in solution. The selective oxidation of HMF within this mixture was performed directly, i.e., without purification, although side products originating from HMF production have been reported to lower catalytic activities in further conversions. ${ }^{33,34}$ Hence, we used a highly active $\mathrm{Au} / \mathrm{ZrO}_{2}$ catalyst prepared by depositionprecipitation as oxidation catalyst ${ }^{32}$ and investigated suitable reaction conditions by adding some of the known side products (Table 1 ).

Table 1. Influence of Glucose and Fructose on the Oxidation of HMF Using a $1.6 \mathrm{wt} \% \mathrm{Au} / \mathrm{ZrO}_{2}$ Catalyst $^{a, b}$

\begin{tabular}{clccc} 
entry & \multicolumn{1}{c}{ substances } & $\begin{array}{c}\text { HMF } \\
\text { conversion }\end{array}$ & $\begin{array}{c}\text { HFCA } \\
\text { yield }\end{array}$ & $\begin{array}{c}\text { FDCA } \\
\text { yield }\end{array}$ \\
1 & pure HMF (cf. ref 32) & 100 & 0 & 79 \\
2 & HMF + glucose & 100 & 34 & 4 \\
3 & HMF + fructose & 100 & 36 & 5
\end{tabular}

${ }^{a}$ Reaction conditions: $125{ }^{\circ} \mathrm{C}, 10$ bar air pressure, $\mathrm{HMF} / \mathrm{NaOH} /$ sugars 1:4:1, $5 \mathrm{~h}$ reaction time, $1 \mathrm{mmol} \mathrm{HMF}$ in $10 \mathrm{~mL}$ of $\mathrm{H}_{2} \mathrm{O}, 98$ $\mathrm{mg}$ of catalyst $(\mathrm{HMF} / \mathrm{Au}=126 \mathrm{~mol} / \mathrm{mol}) .{ }^{b}$ Conversion and yield were calculated based on high-performance liquid chromatography (HPLC) calibrated with external standards.

Since sugars were the main side products in the sucrose hydrolysis and dehydration reaction, the influence of glucose and fructose on the oxidation of pure HMF was first investigated. The results shown in Table 1 reveal that the presence of these sugars drastically decreases the yield of FDCA and that similar amounts of intermediate 5-hydroxymethyl-2-furancarboxylic acid (HFCA) (yield 35\%) are obtained instead. The little amount of FDCA that is produced is in the range of blank experiments. In the next step, we tried to optimize the reaction conditions for HMF oxidation in the presence of fructose.

To further understand the catalytic system, additional parameters were investigated. The influence of air pressure on the yield of FDCA in the presence of fructose is shown in Figure 1a. Although the lower oxygen concentration makes air a more demanding oxidant compared to pure oxygen, it was used in this study to avoid hazardous reaction conditions and because it is more sustainable.

We observed that increasing air pressure shows a positive effect on product yield. At lower air pressures ( $<30$ bar air), mostly the intermediate product HFCA is formed. Interestingly, the yield of HFCA remains constant up to $30 \mathrm{bar}$, while the yield of FDCA increases. The increasing carbon balance together with an increase in FDCA yield to $72 \%$ at 40 bar shows that increasing air pressure facilitates HMF oxidation. The literature mostly reports the oxidation of bio-based HMF using pure $\mathrm{O}_{2}$ at elevated pressure. ${ }^{33,40,42,65}$ Since HMF is unstable in basic aqueous solution, uncharacterized humins are generated under such conditions, which is probably the reason for carbon balances below $100 \%$. Compared to our previous studies without additional fructose, ${ }^{32}$ the negative influence of fructose on the oxidation of HMF is obvious. Without additional fructose, 76\% FDCA was formed at 35 bar using one-third of the HMF-to-Au molar ratio over the same $\mathrm{Au} /$ $\mathrm{ZrO}_{2}$ catalyst. Hence, more catalyst needs to be used (i.e., lower HMF-to-metal ratios) when impure HMF solutions are applied for FDCA synthesis. ${ }^{39-42}$ With a further increase in pressure to 50 bar, a decrease in the FDCA yield was observed. 

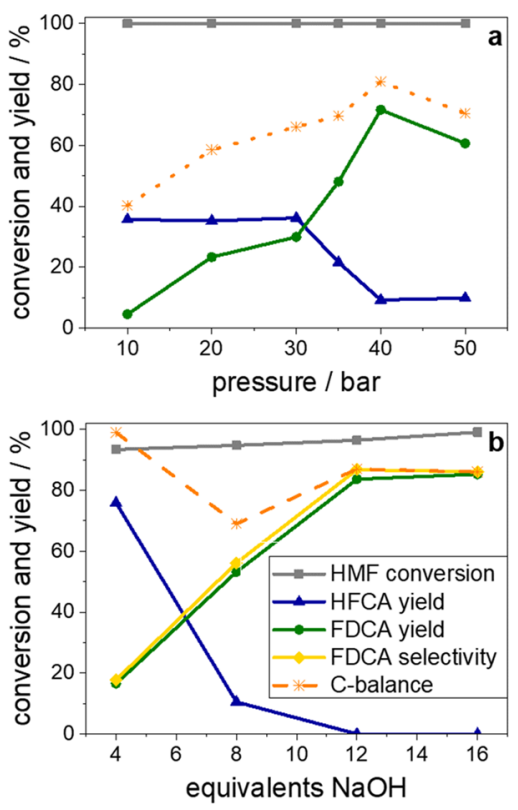

Figure 1. (a) Influence of air pressure on the oxidation of HMF in the presence of fructose. Reaction conditions: $125{ }^{\circ} \mathrm{C}, \mathrm{HMF} / \mathrm{NaOH} /$ fructose $1: 4: 1,5 \mathrm{~h}$ reaction time, $1 \mathrm{mmol} \mathrm{HMF}$ in $10 \mathrm{~mL}$ of $\mathrm{H}_{2} \mathrm{O}, 98$ $\mathrm{mg}$ of catalyst $(\mathrm{HMF} / \mathrm{Au}=126 \mathrm{~mol} / \mathrm{mol})$. (b) Influence of $\mathrm{NaOH}$ addition on the oxidation of $\mathrm{HMF}$ in a solution directly produced from sucrose over $1.6 \mathrm{wt} \% \mathrm{Au} / \mathrm{ZrO}_{2}$. Reaction conditions: $125{ }^{\circ} \mathrm{C}$, $40 \mathrm{bar}$ air pressure, $5 \mathrm{~h}$ reaction time, $0.3 \mathrm{mmol} \mathrm{HMF}$ in $10 \mathrm{~mL}$ of reaction solution, $98 \mathrm{mg}$ of catalyst $(\mathrm{HMF} / \mathrm{Au}=38 \mathrm{~mol} / \mathrm{mol})$.

In the next step, a sucrose hydrolysis/dehydration solution was studied as a feedstock without intermediate purification. Besides fructose and HMF, this solution contained some glucose and traces of xylose, levulinic acid, and formic acid. ${ }^{10}$ Since these compounds commonly occur in the synthesis of HMF, our results should be transferable to other biomass feedstock. Because sulfuric acid was used as the dehydration catalyst, it had to be neutralized before the oxidation reaction. For this purpose, a $\mathrm{pH}$ value of 7 was adjusted using $\mathrm{NaOH}$. Additionally, 4 equiv $\mathrm{NaOH}$ with respect to $\mathrm{HMF}$ was added before the reaction. The reaction was carried out considering the previously optimized reaction conditions (Figure 1a) in the presence of fructose. The HMF solutions obtained from sucrose feedstock were less concentrated with $0.03 \mathrm{~mol} \mathrm{~L}^{-1}$ of HMF. Nevertheless, the catalyst mass was kept constant, resulting in a Au-to-HMF molar ratio of 38. HMF was not fully converted, and HFCA was produced with $76 \%$ yield $(81 \%$ selectivity) as the main product (Figure $1 \mathrm{~b}$ and Table S1). FDCA is produced with $17 \%$ yield ( $18 \%$ selectivity). Considering the carbon balance with respect to HMF, the process was very selective with almost no byproduct, i.e., humin, formation. However, the selectivity toward FDCA needed to be improved and thus the reaction conditions were further optimized. As the process was very selective, the reaction time was prolonged to $20 \mathrm{~h}$ in a first attempt (Table S1). Although FDCA yield increased to $46 \%$ (50\% selectivity), the carbon balance decreased overall. Hence, the extended reaction time favors undesired side reactions.

Next, the influence of base on the reaction was investigated as hydroxide ions are required for the oxidation of HMF. ${ }^{66}$ In addition, the presence of other functional groups due to the contaminants might lead to a lower hydroxide-ions concentration. Varying the amount of base under the same reaction conditions (Figure 1b), the conversion of HMF increased to almost $100 \%$ with increase of excess base. Above 8 equiv $\mathrm{NaOH}$ (relative to HMF), a change in selectivity from HFCA to FDCA was observed. In this case, FDCA was produced with $53 \%$ yield, whereas $11 \%$ of HFCA was observed. Furthermore, increasing the amount of base to 12 equiv led to a complete oxidation of HFCA to FDCA, resulting in a yield of $84 \%$. An even higher amount of base did not have any further influence on the yield of FDCA, and the maximum yield seems limited under the chosen reaction conditions. In addition to the yield of FDCA, the selectivity of the reaction also increased to a maximum of $87 \%$.

The production of HFCA using impure HMF solutions can be attributed to the potential deposition of the present impurities on the catalyst surface. ${ }^{37}$ In addition, the presence of further oxidizable groups besides the ones of HMF may also be a reason for this observation. In both cases, the active gold centers are blocked lowering the catalytic activity. Therefore, humins are generated before HMF is able to react on an active site of the catalyst.

Nevertheless, a selective synthesis of FDCA was possible. The yield of FDCA of $84 \%$ obtained under optimized conditions is high in view of the fact that, in addition to HMF, many other undesirable substances were present. As HMF extraction is necessary in other reports, ${ }^{33,37}$ this is a decisive innovative step forward in HMF oxidation. In addition, we were able to establish a process in which, apart from the addition of the catalyst and base, no further operations are required. Therefore, we can directly use the resulting HMF solution since both HMF synthesis and oxidation are performed in water and no solvent mixture ${ }^{38,39}$ or multiphase setup ${ }^{35,36}$ is required, representing another innovation in the field of HMF oxidation.

Possibly, also oxygen availability might be a limiting factor in this reaction since air was used instead of pure oxygen, generally limiting its availability in solution. In addition, its adsorption on the catalyst surface might be hindered by competitive adsorption with the other components in solution. In fact, FDCA yield and, at the same time, the carbon balance increased at higher pressure (Figure 1a) with a higher availability of oxygen in solution.

Increasing the amount of base in the oxidation of HMF produced from sucrose from 4 to 8 equiv led to a decrease in the carbon balance. The carbon balance increased again upon further increase in the amount of base to 12 and 16 equiv. Since hydroxide ions contribute in the catalytic cycle, ${ }^{66}$ increasing their amount facilitates and accelerates the reaction. However, HMF is unstable under basic conditions and thus the drop in selectivity at 8 equiv might be explained by a faster degradation compared to the acceleration in HMF oxidation.

The high yield of FDCA allowed its separation from the reaction solution, although side products from both HMF and FDCA synthesis were present in solution. Acidification of the reaction solution with $\mathrm{HCl}(\mathrm{pH} 2)$, extraction using ethyl acetate, and evaporation of the solvent led to a pure solid product of FDCA avoiding any chromatographic or other purification steps. NMR spectroscopy showed solely the expected ${ }^{1} \mathrm{H}$ NMR signals of FDCA, and gas chromatography analysis confirmed a purity of $94 \%$ (Figure S1). Recrystallization could be used for further purification.

2.2. Multicomponent Polymerization of FDCA. As a third and final step after the production of HMF and FDCA, we investigated Ugi-multicomponent polymerizations, thus 
Table 2. Ugi-4CR Polymerization with Commercial and Renewable FDCA; 1,10-Diaminodecane, Isobutyraldehyde, and tertButyl Isocyanide Were Used as Further Components

\begin{tabular}{|c|c|c|c|c|}
\hline entry & concentration $\left(\mathrm{mol} \mathrm{L}^{-1}\right)$ & solvent & $M_{\mathrm{n}}\left(\mathrm{g} \mathrm{mol}^{-1}\right)^{a}$ & $Đ$ \\
\hline 1 & 0.5 & THF/MeOH 2:1 & 800 & 1.55 \\
\hline 2 & 0.5 & {$[\mathrm{EMIM}] \mathrm{BF}_{4}$} & 2,800 & 1.35 \\
\hline 3 & 0.5 & {$[\mathrm{EMIM}] \mathrm{BF}_{4} / \mathrm{MeOH} 4: 1$} & 2,200 & 1.21 \\
\hline 4 & 0.5 & {$[\mathrm{EMIM}] \mathrm{BF}_{4} / \mathrm{MeOH} 1: 1$} & 5,450 & 1.88 \\
\hline 5 & 0.5 & {$[\mathrm{EMIM}] \mathrm{BF}_{4} / \mathrm{MeOH} 1: 4$} & 5,000 & 2.09 \\
\hline 6 & 2 & $\mathrm{MeOH}$ & 5,550 & 1.61 \\
\hline 7 & 2 & $\mathrm{MeOH} / \mathrm{DMSO} 3: 1$ & 6,000 & 1.69 \\
\hline 8 & 2 & $\mathrm{MeOH} / \mathrm{DMSO} 1: 1$ & 5,500 & 1.57 \\
\hline 9 & 2 & $\mathrm{MeOH} / \mathrm{DMSO} 1: 3$ & 4,900 & 1.50 \\
\hline 10 & 1 & $\mathrm{MeOH}$ & 6,700 & 1.72 \\
\hline 11 & 1 & $\mathrm{MeOH} / \mathrm{DMSO} 3: 1$ & 7,800 & 1.78 \\
\hline 12 & 1 & $\mathrm{MeOH} / \mathrm{DMSO}$ 1:1 & 7,300 & 1.76 \\
\hline 13 & 1 & $\mathrm{MeOH} / \mathrm{DMSO} 1: 3$ & 7,900 & 1.94 \\
\hline 14 & 0.5 & $\mathrm{MeOH}$ & 6,700 & 1.83 \\
\hline 15 & 0.5 & $\mathrm{MeOH} / \mathrm{DMSO} 3: 1$ & 8,850 & 1.85 \\
\hline 16 & 0.5 & $\mathrm{MeOH} / \mathrm{DMSO}$ 1:1 & 8,500 & 2.43 \\
\hline 17 & 0.5 & $\mathrm{MeOH} / \mathrm{DMSO}$ 1:3 & 10,100 & 3.29 \\
\hline 18 & 0.5 & $\mathrm{MeOH} / \mathrm{DMSO} 1: 3^{b}$ & 8,800 & 2.01 \\
\hline 19 & 0.5 & $\mathrm{MeOH} / \mathrm{DMSO} 1: 3^{c}$ & 11,100 & 2.73 \\
\hline
\end{tabular}

${ }^{a}$ Gel permeation chromatography (GPC) results of the reaction mixture after precipitation in water, however without separation of the formed macrocycle. The macrocycle was excluded from the integration for better comparison the polymer fraction. ${ }^{b}$ FDCA as catalytically synthesized herein was utilized. ${ }^{c}$ The reaction was scaled up to $7.68 \mathrm{~g}$ theoretical yield of the polymer; average molecular weight after precipitation.

introducing new application possibilities for FDCA. First, we optimized the reaction conditions by varying the solvent and concentration of the components using commercial FDCA (purity $>95 \%$ ), as shown in Table 2 .

As reported previously, a different solvent mixture is beneficial for this multicomponent polymerization due to differences in solubility of the monomers and polymers, specific for each monomer combination of bifunctional and monofunctional acids, amines, aldehydes, and isocyanides. ${ }^{67}$ Since tetrahydrofuran (THF) provides good solubility for most polymers and methanol is a suitable protic solvent for Ugi reactions, this combination was first evaluated. However, THF was not beneficial here (Table 2, entry 1 ), as the major part of FDCA did not dissolve. To provide a good solubility for the aromatic and polar FDCA, the ionic liquid 1-ethyl-3methylimidazolium tetrafluoroborate $\left([\mathrm{EMIM}] \mathrm{BF}_{4}\right)$ was evaluated without co-solvent (Table 2, entry 2 ) and with methanol as co-solvent (Table 2, entries 3-5). A molecular weight of $M_{n}$ $=5,450 \mathrm{~g} \mathrm{~mol}^{-1}(Ð=1.88$, Table 2 , entry 4) was achieved. However, various impurities were identified by ${ }^{1} \mathrm{H}$ NMR spectroscopy, which could not be separated by precipitation, indicating side reactions during polymerization. In contrast, pure methanol led to a higher molecular weight at the concentration of $0.5 \mathrm{~mol} \mathrm{~L}^{-1}\left(M_{\mathrm{n}}=6,700 \mathrm{~g} \mathrm{~mol}^{-1} ; Ð=1.83\right.$, Table 2, entry 15) without any side reactions. A further improvement was achieved using mixtures of methanol and dimethyl sulfoxide (DMSO) with the highest molecular weight at a ratio of $\mathrm{MeOH} / \mathrm{DMSO} 1: 3$ (Table 2, entry 18). Interestingly, a higher concentration, which is usually beneficial for polymer formation, led to a lower molecular weight for all evaluated ratios of $\mathrm{MeOH} / \mathrm{DMSO}$ as well as pure $\mathrm{MeOH}$ (Table 2, entries 6-13). Compared to commercial FDCA, the FDCA catalytically synthesized from HMF as discussed above (94\% purity) yielded a only slightly lower molecular weight $\left(M_{\mathrm{n}}=8,800 \mathrm{~g} \mathrm{~mol}^{-1} ; Ð=2.01\right.$, Table 2, entry 18). After the optimization, the reaction was scaled up. The polymer was further purified by precipitation in water to separate DMSO and afterward in petrol ether at ca. $-30{ }^{\circ} \mathrm{C}$ to separate lowmolecular-weight oligomers and macrocycles formed due to the relatively high dilution $\left(0.5 \mathrm{~mol} \mathrm{~L}^{-1}\right)$. After precipitation, a molecular weight of $M_{\mathrm{n}}=11,100 \mathrm{~g} \mathrm{~mol}^{-1}(\bigoplus=2.73$, Table 2, entry 19) was obtained. As the mixture is comparably diluted, in addition to the high-molecular-weight polymer, significant amounts of twofold and threefold macrocycles were formed, which is well known from the literature ${ }^{68}$ and can also be exploited to synthesize, e.g., polymacrocycles, in two steps (Figure 2, bottom). ${ }^{69}$

The macrocycles were identified by size exclusion chromatography-electrospray ionization mass spectrometry (SEC-ESI MS) (twofold macrocycle $[\mathrm{M}+\mathrm{H}]^{+}$(calculated): 603.4480, $[\mathrm{M}+\mathrm{H}]^{+}$(obtained): 603.4481; fourfold macrocycle $[\mathrm{M}+\mathrm{H}]^{+}$(calculated): 1205.8887, $[\mathrm{M}+\mathrm{H}]^{+}$ (obtained): 1205.8888) and can be assigned in the SEC trace (Figure 2, bottom) at retention times of $19.5 \mathrm{~min}$ (twofold macrocycle) and $18.3 \mathrm{~min}$ (fourfold macrocycle). Additionally, the twofold macrocycle was isolated by column chromatography and again measured in SEC confirming the peak assignment. The chemical structure of the polymer was confirmed by ${ }^{1} \mathrm{H}$ and ${ }^{13} \mathrm{C}$ NMR spectroscopy (Figure 2) as well as correlation spectroscopy and ${ }^{1} \mathrm{H}-{ }^{13} \mathrm{C}$ heteronuclear single quantum coherence (HSQC) spectroscopy. Thermal analysis [differential scanning calorimetry (DSC)] reveals a glass transition at $82.2{ }^{\circ} \mathrm{C}$ and no melting point within the measured temperature range of -85 to $250{ }^{\circ} \mathrm{C}$. Summarizing the polymerization results, catalytically obtained FDCA is a suitable monomer for direct multicomponent polymerization, resulting in novel polymer structures as well as interesting macrocyclic products.

\section{CONCLUSIONS}

In conclusion, a process chain is established herein based on HMF produced from sucrose as an example for a mixture 

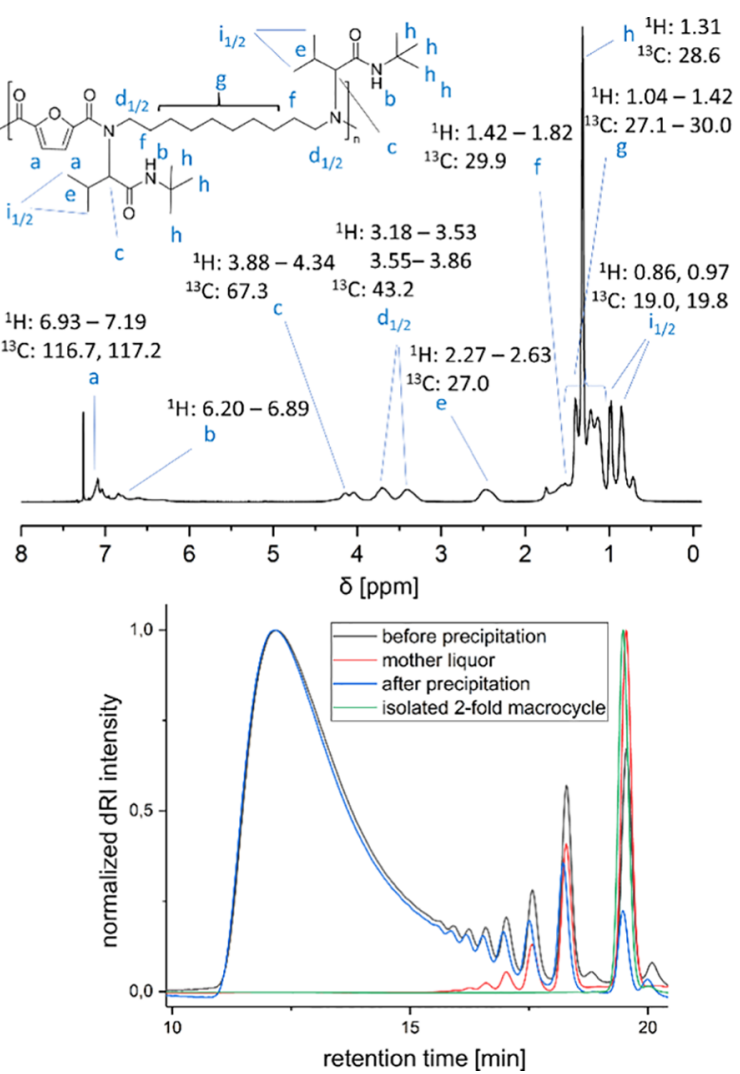

Figure 2. ${ }^{1} \mathrm{H}$ NMR spectrum (in $\mathrm{CDCl}_{3}$ ) of the precipitated Ugi polymer (top) and size exclusion chromatography (SEC) trace (bottom) of the polymer before precipitation, after precipitation, the isolated macrocycle, and the mother liquor of the precipitation. The chemical shifts in the ${ }^{1} \mathrm{H}$ NMR and via heteronuclear single quantum coherence (HSQC) correlated shifts of the ${ }^{13} \mathrm{C}$ NMR spectrum are given in parts per million (ppm).

obtained from sugar-based feedstock. The resulting HMF was directly and selectively oxidized to FDCA without purification and, thus, despite the presence of impurities, which represents a novelty in this field. After acidification and extraction with ethyl acetate, FDCA was available in a purity that allows polymerization. The purity can be increased by recrystallization. As a demonstration example and to evaluate a new application possibility for FDCA, the Ugi-4CR as novel process has been conducted using commercially available FDCA and FDCA that was produced in the catalytic process. Although FDCA could be produced in these preliminary studies in high yield and purity, the sustainability of the process remains challenging considering the 12 principles of green chemistry. ${ }^{70}$ Obviously, we were able to use a renewable feedstock and nontoxic chemicals in FDCA synthesis, the reaction was heterogeneously catalyzed in aqueous medium, and we could circumvent purification after step 1 . In addition, air was used as green oxidant. However, to further optimize the sustainability, the use of base in FDCA synthesis should be minimized by using a solid base or by recycling it. Furthermore, it would be desirable to extend the process to other sugar-based feedstocks and the polymerization should be further optimized with regard to sustainability, for example, by changing the solvent mixtures.

\section{EXPERIMENTAL SECTION}

4.1. Materials. All chemicals for the catalytic synthesis of FDCA were of analytical grade and have been used without further purification: HMF, FDCA (Sigma-Aldrich), HFCA, $\mathrm{NaOH}$, sucrose (Merck), 5-formyl-2-furoic acid, 2,5-diformylfurane (TCI Chemicals), $\mathrm{D}(-)$-fructose, $\mathrm{D}(+)$-glucose (VWR Chemicals), $\mathrm{HAuCl}_{4} \cdot 3 \mathrm{H}_{2} \mathrm{O}, \mathrm{H}_{2} \mathrm{SO}_{4}, \mathrm{ZrO}_{2} 1 / 8$ in. pellets (Alfa Aesar) and synthetic air (Air Liquide). All solvents applied in the multicomponent polymerization of FDCA were used in HPLC grade. The following chemicals were used as received: 2,5-furandicarboxylic acid (FDCA, OXCHEM, >95\%), 1,10diaminodecane (TCI, $>98.0 \%)$, isobutyraldehyde ( $\geq 99 \%$, Sigma-Aldrich), tert-butyl isocyanide (Sigma-Aldrich, 98\%), and 1-ethyl-3-methylimidazolium tetrafluoroborate ([EMIM]$\mathrm{BF}_{4}$, Sigma-Aldrich, $\geq 99.0 \%$ ).

4.2. Methods. The oxidation of HMF was carried out in self-built stainless steel autoclaves $(52 \mathrm{~mL}$ with Teflon inlet, max. pressure of 200 bar at $350{ }^{\circ} \mathrm{C}$, magnetically stirred at maximum speed) equipped with heating sleeves, and the solutions were analyzed via HPLC (Hitachi Primaide, Aminex $\mathrm{HPX}-87 \mathrm{H}$ column, solvent $5 \mathrm{mM} \mathrm{H}_{2} \mathrm{SO}_{4}, 50{ }^{\circ} \mathrm{C}$ at $0.5 \mathrm{~mL}$ $\mathrm{min}^{-1}$, refractive index and diode array detectors). The ${ }^{1} \mathrm{H}$ NMR and ${ }^{13} \mathrm{C}$ NMR spectra were recorded using a BRUKER Prodigy spectrometer (operating at $400 \mathrm{MHz}$ for ${ }^{1} \mathrm{H}$ and 100 $\mathrm{MHz}$ for ${ }^{13} \mathrm{C}$ ). Molecular weight distributions were determined using an SEC system LC-20A from Shimadzu equipped with an SIL-20A autosampler and an RID-10A refractive index detector in THF (flow rate, $1.0 \mathrm{~mL} \mathrm{~min}^{-1}$ ) at $50^{\circ} \mathrm{C}$. IR spectra were recorded on a BRUKER $\alpha$-p instrument in the frequency range of $3997.41-373.828 \mathrm{~cm}^{-1}$ applying attenuated total reflection (ATR) technology. DSC experiments were carried out with a DSC STARe system (Mettler Toledo) operating under nitrogen atmosphere and employing a sample mass of approximately $5.0 \mathrm{mg}$. The glass transition $\left(T_{\mathrm{g}}\right)$ was recorded on the second heating scan by using the following method: cooling from room temperature to $-85^{\circ} \mathrm{C}$, heating from -85 to $250{ }^{\circ} \mathrm{C}$ at $10{ }^{\circ} \mathrm{C} \mathrm{min}^{-1}$, cooling from 250 to $-85^{\circ} \mathrm{C}$ at 10 ${ }^{\circ} \mathrm{C} \mathrm{min}{ }^{-1}$, and heating from -85 to $250{ }^{\circ} \mathrm{C}$ at $10{ }^{\circ} \mathrm{C} \mathrm{min}^{-1}$. Thin-layer chromatography (TLC) aluminum foils with fluorescence indicator from MERCK (TLC silica gel 60, $F_{254}$, layer thickness: $0.25 \mathrm{~mm}$ ) were employed. Size exclusion chromatography-electrospray ionization mass spectrometry (SEC-ESI MS) was recorded on an LTQ Orbitrap XL Q Exactive mass spectrometer (Thermo Fisher Scientific, San Jose, CA) equipped with a HESI II probe.

4.3. Synthesis of HMF. The synthesis of HMF was performed as described elsewhere. ${ }^{10}$ In brief, an aqueous solution of $2 \mathrm{wt} \%$ sucrose and $0.005 \mathrm{M}$ sulfuric acid was fed into a tubular reactor operating at $200{ }^{\circ} \mathrm{C}$ and 25 bar. The hydrodynamic residence time was $10 \mathrm{~min}$. The resulting solution from the reactor was cooled in a heat exchanger and stored at $4{ }^{\circ} \mathrm{C}$. A carbon balance showed that the carbon from the sucrose feedstock was converted to $26.6 \% \mathrm{HMF}, 48.6 \%$ glucose, $17.2 \%$ fructose, $1.4 \%$ levulinic acid, $1.2 \%$ furfural, and 4.9\% undefined side products.

4.4. Oxidation of HMF. The batchwise oxidation of HMF was performed using a $\mathrm{Au} / \mathrm{ZrO}_{2}$ catalyst prepared by deposition-precipitation method. ${ }^{32}$ For more details on the preparation procedure and thorough catalyst characterization, see ref 32. For testing the influence of carbohydrates on the FDCA yield, $1 \mathrm{mmol}$ (126 mg) HMF and an equimolar amount of glucose or fructose were dissolved in water before 
the desired amount of $\mathrm{NaOH}$ was added as a $2.5 \mathrm{M}$ solution to give a total volume of $10 \mathrm{~mL}$. For the oxidation of HMF produced from sucrose, the resulting solutions from the continuous HMF synthesis were brought to a $\mathrm{pH}$ of 7 prior to oxidation using $\mathrm{NaOH}$. The desired excess amount of $\mathrm{NaOH}$ was then added to $10 \mathrm{~mL}$ of this solution. In both cases, the solid catalyst was then added, the reactors were closed, purged three times with synthetic air, and pressurized to a desired value. The point of first reaching the desired reaction temperature was set as the starting point of the reaction $(t=$ 0 , ca. $15 \mathrm{~min}$ ). The reactors were cooled to room temperature in an ice bath after the reaction, depressurized, and the solid catalyst was separated from the solutions by decantation. Samples before and after reaction were taken, filtered with a $0.45 \mu \mathrm{m}$ Pall Teflon filter, and diluted for HPLC analysis. The HPLC was calibrated using solutions with different concentrations of HMF, HFCA, FDCA, 2,5-diformylfuran, and 5formyl-2-furancarboxylic acid.

4.5. Optimization of the Ugi-4C Polymerization. Decane-1,10-diamine (221 mg, $1.28 \mathrm{mmol}, 1.00$ equiv) was dissolved in the respective solvent mixture $(2.56 \mathrm{~mL}$ total volume for $0.5 \mathrm{M}, 1.28 \mathrm{~mL}$ total volume for $1 \mathrm{M}, 0.64 \mathrm{~mL}$ total volume for $2 \mathrm{M})$. Isobutyraldehyde $(351 \mu \mathrm{L}, 277 \mathrm{mg}, 3.84$ mmol, 3.00 equiv) was added, and the mixture was stirred for $30 \mathrm{~min}$ at room temperature to preform the imine. Furan-2,5dicarboxylic acid (200 mg, $1.28 \mathrm{mmol}, 1.00$ equiv) was suspended in the mixture and tert-butyl isocyanide $(435 \mu \mathrm{L}$, $320 \mathrm{mg}, 3.84 \mathrm{mmol}, 3.00$ equiv) was added. After stirring at $500 \mathrm{rpm}$ for 3 days, the mixture was precipitated in water to separate the high-boiling solvents, yielding a sticky polymer, which was dried in vacuo before GPC analysis.

4.6. Optimized Polymerization and Scale-Up. Decane1,10-diamine ( $2.21 \mathrm{~g}, 12.8 \mathrm{mmol}, 1.00$ equiv) was dissolved in a mixture of $19.2 \mathrm{~mL}$ of DMSO and $6.4 \mathrm{~mL}$ of methanol. Isobutyraldehyde ( $3.51 \mathrm{~mL}, 2.77 \mathrm{~g}, 38.4 \mathrm{mmol}, 3.00$ equiv) was added, and the mixture was stirred for $30 \mathrm{~min}$ at room temperature to preform the imine. Furan-2,5-dicarboxylic acid ( $2.00 \mathrm{~g}, 12.8 \mathrm{mmol}, 1.00$ equiv) was suspended in the mixture, and tert-butyl isocyanide $(4.35 \mathrm{~mL}, 3.20 \mathrm{~g}, 38.4 \mathrm{mmol}, 3.00$ equiv) was added. After stirring at $500 \mathrm{rpm}$ for 3 days, the mixture was precipitated in water, yielding a sticky polymer. The crude polymer was dissolved in acetone and precipitated in petrol ether to separate the macrocycle and low-molecularweight oligomers, yielding a slightly yellow voluminous polymer (5.77 g, 75\%) after drying.

${ }^{1} \mathrm{H}$ NMR: $\left(400 \mathrm{MHz}, \mathrm{CDCl}_{3}\right): \delta(\mathrm{ppm})=7.19-6.93(\mathrm{~m}$, 2H, CArH), 6.89-6.20 (m, 2H, NH), 4.34-3.88 (m, 2H, $\mathrm{CH}-\mathrm{CONH}), 3.86-3.55\left(\mathrm{~m}, 2 \mathrm{H}, \mathrm{CH}_{2}-\mathrm{N}\right), 3.53-3.18(\mathrm{~m}$, $2 \mathrm{H}, \mathrm{CH}_{2}-\mathrm{N}$ ), 2.63-2.27 (m, 2H, CH- $\left.\mathrm{CH}_{3}\right), 1.82-1.42(\mathrm{~m}$, $\left.4 \mathrm{H}, \mathrm{CH}_{2}-\mathrm{CH}_{2}-\mathrm{N}\right), 1.31\left(\mathrm{~s}, 18 \mathrm{H}, \mathrm{Cq}-\mathrm{CH}_{3}\right), 1.42-1.04(\mathrm{~m}$, $\left.12 \mathrm{H}, \mathrm{CH}_{2}\right), 1.03-0.91\left(\mathrm{~m}, 6 \mathrm{H}, \mathrm{CH}_{3}-\mathrm{CH}\right), 0.90-0.63(\mathrm{~m}$, $\left.6 \mathrm{H}, \mathrm{CH}_{3}-\mathrm{CH}\right) ;{ }^{13} \mathrm{C}$ NMR: $\left(100 \mathrm{MHz}, \mathrm{CDCl}_{3}\right): \delta(\mathrm{ppm})=$ $169.3(\mathrm{CO}-\mathrm{NH}), 168.6(\mathrm{CO}-\mathrm{NH}), 161.0(\mathrm{CAr}-\mathrm{CO}-\mathrm{N})$, 148.9 (CAr-CO), $117.2(\mathrm{CArH}), 116.7$ (CArH), $67.3(\mathrm{CH}-$ $\mathrm{CONH}), 43.2\left(\mathrm{CH}_{2}-\mathrm{N}\right), 30.0-27.1\left(\mathrm{CH}_{2}\right), 28.6\left(\mathrm{Cq}-\mathrm{CH}_{3}\right)$, $27.0\left(\mathrm{CH}-\mathrm{CH}_{3}\right), 19.8\left(\mathrm{CH}-\mathrm{CH}_{3}\right), 19.0\left(\mathrm{CH}-\mathrm{CH}_{3}\right)$; IR (ATR): 3304.9, 2963.9, 2927.1, 2855.9, 1674.9, 1614.9, $1529.5,1454.1,1416.7,1389.6,1362.5,1337.5,1289.9$, $1223.7,1126.9,1055.2,929.9,816.4,756.4,484.9 \mathrm{~cm}^{-1} ; T_{\mathrm{g}}$ $=82.2{ }^{\circ} \mathrm{C}$.

\section{ASSOCIATED CONTENT}

\section{Supporting Information}

The Supporting Information is available free of charge on the ACS Publications website at DOI: 10.1021/acsomega.9b02373.

More detailed description of the used methods; further aspects on FDCA synthesis; and characterization of FDCA produced from sucrose (PDF)

\section{AUTHOR INFORMATION}

\section{Corresponding Authors}

*E-mail: m.a.r.meier@kit.edu (M.A.R.M.).

*E-mail: grunwaldt@kit.edu (J.-D.G.).

ORCID

Michael A. R. Meier: 0000-0002-4448-5279

Jan-Dierk Grunwaldt: 0000-0003-3606-0956

\section{Author Contributions}

The manuscript was written through contributions of all authors. All authors have given approval to the final version of the manuscript.

\section{Funding}

This work was funded and supported by KIT. In addition, J.D.G. and O.R.S. acknowledge funding from the recently accepted FNR-project (KEFIP, FKZ: 22010718).

Notes

The authors declare no competing financial interest.

\section{ACKNOWLEDGMENTS}

The authors thank Rieke Schulte for skillful technical assistance.

\section{REFERENCES}

(1) Nikolau, B. J.; Perera, M. A. D. N.; Brachova, L.; Shanks, B. Platform biochemicals for a biorenewable chemical industry. Plant J. 2008, 54, 536-545.

(2) van Putten, R.-J.; van der Waal, J. C.; de Jong, E.; Rasrendra, C. B.; Heeres, H. J.; de Vries, J. G. Hydroxymethylfurfural, a Versatile Platform Chemical Made from Renewable Resources. Chem. Rev. 2013, 113, 1499-1597.

(3) Henrich, E.; Dahmen, N.; Dinjus, E.; Sauer, J. The role of biomass in a future world without fossil fuels. Chem. Ing. Tech. 2015, 87, 1667-1685.

(4) Hellinger, M.; Baier, S.; Mortensen, P. M.; Kleist, W.; Jensen, A. D.; Grunwaldt, J.-D. Continuous Catalytic Hydrodeoxygenation of Guaiacol over $\mathrm{Pt} / \mathrm{SiO}_{2}$ and $\mathrm{Pt} / \mathrm{H}-\mathrm{MFI}-90$. Catalysts 2015, 5, 11521166.

(5) Ragauskas, A. J.; Williams, C. K.; Davison, B. H.; Britovsek, G.; Cairney, J.; Eckert, C. A.; Frederick, W. J., Jr.; Hallett, J. P.; Leak, D. J.; Liotta, C. L.; et al. The path forward for biofuels and biomaterials. Science 2006, 311, 484-489.

(6) Corma, A.; Iborra, S.; Velty, A. Chemical Routes for the Transformation of Biomass into Chemicals. Chem. Rev. 2007, 107, 2411-2502.

(7) Rosatella, A. A.; Simeonov, S. P.; Frade, R. F. M.; Afonso, C. A. M. 5-Hydroxymethylfurfural (HMF) as a building block platform: Biological properties, synthesis and synthetic applications. Green Chem. 2011, 13, 754-793.

(8) Steinbach, D.; Kruse, A.; Sauer, J. Pretreatment technologies of lignocellulosic biomass in water in view of furfural and 5hydroxymethylfurfural production-A review. Biomass Convers. Biorefin. 2017, 7, 247-274.

(9) Kuster, B. F. M. 5-Hydroxymethylfurfural (HMF). A Review Focussing on its Manufacture. Starch/Stärke 1990, 42, 314-321. 
(10) Steinbach, D.; Kruse, A.; Sauer, J.; Vetter, P. Sucrose Is a Promising Feedstock for the Synthesis of the Platform Chemical Hydroxymethylfurfural. Energies 2018, 11, No. 645.

(11) Chatterjee, M.; Ishizaka, T.; Kawanami, H. Selective hydrogenation of 5-hydroxymethylfurfural to 2,5-bis-(hydroxymethyl)furan using Pt/MCM-41 in an aqueous medium: a simple approach. Green Chem. 2014, 16, 4734-4739.

(12) Chatterjee, M.; Ishizaka, T.; Chatterjee, A.; Kawanami, H. Dehydrogenation of 5-hydroxymethylfurfural to diformylfuran in compressed carbon dioxide: an oxidant free approach. Green Chem. 2017, 19, 1315-1326.

(13) Saha, B.; Bohn, C. M.; Abu-Omar, M. M. Zinc-Assisted Hydrodeoxygenation of Biomass-Derived 5-Hydroxymethylfurfural to 2,5-Dimethylfuran. ChemSusChem 2014, 7, 3095-3101.

(14) Hengst, K.; Schubert, M.; Kleist, W.; Grunwaldt, J.-D. Hydrodeoxygenation of Lignocellulose-Derived Platform Molecules. In Catalytic Hydrogenation for Biomass Valorization; Rinaldi, R., Ed.; Royal Society of Chemistry, 2015; Vol. 1, pp 125-150.

(15) Werpy, T.; Bozell, J.; Petersen, G.; Aden, A.; Holladay, J.; White, J.; Manheim, A.; Elliot, D.; Lasure, L.; Jones, S.; Gerber, M.; Ibsen, K.; Lumberg, L.; Kelley Top Value Added Chemicals from Biomass: Results of Screening for Potential Candidates from Sugars and Synthesis Gas; U.S. Department of Energy: Washington, DC, 2004; Vol. 1.

(16) Bozell, J. J.; Petersen, G. R. Technology development for the production of biobased products from biorefinery carbohydrates-the US Department of Energy's “Top 10" revisited. Green Chem. 2010, 12, 539-554.

(17) Ventura, M.; Dibenedetto, A.; Aresta, M. Heterogeneous catalysts for the selective aerobic oxidation of 5-hydroxymethylfurfural to added value products in water. Inorg. Chim. Acta 2018, 470, 11-21. (18) Zhang, Z.; Huber, G. W. Catalytic oxidation of carbohydrates into organic acids and furan chemicals. Chem. Soc. Rev. 2018, 47, 1351-1390.

(19) Krystof, M.; Pérez-Sánchez, M.; Domínguez de María, P. Lipase-Mediated Selective Oxidation of Furfural and 5-Hydroxymethylfurfural. ChemSusChem 2013, 6, 826-830.

(20) Koopman, F.; Wierckx, N.; de Winde, J. H.; Ruijssenaars, H. J. Efficient whole-cell biotransformation of 5-(hydroxymethyl)furfural into FDCA, 2,5-furandicarboxylic acid. Bioresour. Technol. 2010, 101, 6291-6296.

(21) Chadderdon, D. J.; Xin, L.; Qi, J.; Qiu, Y.; Krishna, P.; More, K. L.; Li, W. Electrocatalytic oxidation of 5-hydroxymethylfurfural to 2,5furandicarboxylic acid on supported $\mathrm{Au}$ and $\mathrm{Pd}$ bimetallic nanoparticles. Green Chem. 2014, 16, 3778-3786.

(22) Nam, D.-H.; Taitt, B. J.; Choi, K.-S. Copper-Based Catalytic Anodes To Produce 2,5-Furandicarboxylic Acid, a Biomass-Derived Alternative to Terephthalic Acid. ACS Catal. 2018, 8, 1197-1206.

(23) Partenheimer, W.; Grushin, V. V. Synthesis of 2,5Diformylfuran and Furan-2,5-Dicarboxylic Acid by Catalytic AirOxidation of 5-Hydroxymethylfurfural. Unexpectedly Selective Aerobic Oxidation of Benzyl Alcohol to Benzaldehyde with Metal=Bromide Catalysts. Adv. Synth. Catal. 2001, 343, 102-111.

(24) de Diego, C. M.; Schammel, W. P.; Dam, M. A.; Gruter, G. J. M. Method for the preparation of 2,5-furandicarboxylic acid and esters thereof. US8519167B22013.

(25) Sajid, M.; Zhao, X.; Liu, D. Production of 2, 5-furandicarboxylic acid (FDCA) from 5-hydroxymethyl furfural (HMF): A recent progress focusing on the chemical-catalytic routes. Green Chem. 2018, $20,5427-5453$.

(26) Zhang, Z.; Deng, K. Recent Advances in the Catalytic Synthesis of 2,5-Furandicarboxylic Acid and Its Derivatives. ACS Catal. 2015, 5, 6529-6544.

(27) Casanova, O.; Iborra, S.; Corma, A. Biomass into Chemicals: Aerobic Oxidation of 5-Hydroxymethyl-2-furfural into 2,5-Furandicarboxylic Acid with Gold Nanoparticle Catalysts. ChemSusChem 2009, 2, 1138-1144.

(28) Gorbanev, Y. Y.; Klitgaard, S. K.; Woodley, J. M.; Christensen, C. H.; Riisager, A. Gold-Catalyzed Aerobic Oxidation of 5-
Hydroxymethylfurfural in Water at Ambient Temperature. ChemSusChem 2009, 2, 672-675.

(29) Cai, J.; Ma, H.; Zhang, J.; Song, Q.; Du, Z.; Huang, Y.; Xu, J. Gold Nanoclusters Confined in a Supercage of Y Zeolite for Aerobic Oxidation of HMF under Mild Conditions. Chem. - Eur. J. 2013, 19, 14215-14223.

(30) Miao, Z.; Zhang, Y.; Pan, X.; Wu, T.; Zhang, B.; Li, J.; Yi, T.; Zhang, Z.; Yang, $\mathrm{X}$. Superior catalytic performance of $\mathrm{Ce}_{1-\mathrm{x}} \mathrm{Bi}_{\mathrm{x}} \mathrm{O}_{2-\delta}$ solid solution and $\mathrm{Au} / \mathrm{Ce}_{1-\mathrm{x}} \mathrm{Bi}_{\mathrm{x}} \mathrm{O}_{2-\delta}$ for 5-hydroxymethylfurfural conversion in alkaline aqueous solution. Catal. Sci. Technol. 2015, 5, 1314-1322.

(31) Gupta, N. K.; Nishimura, S.; Takagaki, A.; Ebitani, K. Hydrotalcite-supported gold-nanoparticle-catalyzed highly efficient base-free aqueous oxidation of 5-hydroxymethylfurfural into 2,5furandicarboxylic acid under atmospheric oxygen pressure. Green Chem. 2011, 13, 824-827.

(32) Schade, O. R.; Kalz, K. F.; Neukum, D.; Kleist, W.; Grunwaldt, J.-D. Supported gold- and silver-based catalysts for the selective aerobic oxidation of 5-(hydroxymethyl)furfural to 2,5-furandicarboxylic acid and 5-hydroxymethyl-2-furancarboxylic acid. Green Chem. 2018, 20, 3530-3541.

(33) Gallo, J. M. R.; Alonso, D. M.; Mellmer, M. A.; Dumesic, J. A. Production and upgrading of 5-hydroxymethylfurfural using heterogeneous catalysts and biomass-derived solvents. Green Chem. 2013, $15,85-90$.

(34) Wettstein, S. G.; Alonso, D. M.; Chong, Y.; Dumesic, J. A. Production of levulinic acid and gamma-valerolactone (GVL) from cellulose using GVL as a solvent in biphasic systems. Energy Environ. Sci. 2012, 5, 8199-8203.

(35) Kröger, M.; Prüße, U.; Vorlop, K.-D. A new approach for the production of 2,5-furandicarboxylic acid by in situ oxidation of 5hydroxymethylfurfural starting from fructose. Top. Catal. 2000, 13, $237-242$.

(36) Yi, G.; Teong, S. P.; Zhang, Y. The Direct Conversion of Sugars into 2,5-Furandicarboxylic Acid in a Triphasic System. ChemSusChem 2015, 8, 1151-1155.

(37) Yi, G.; Teong, S. P.; Li, X.; Zhang, Y. Purification of BiomassDerived 5-Hydroxymethylfurfural and Its Catalytic Conversion to 2,5Furandicarboxylic Acid. ChemSusChem 2014, 7, 2131-2135.

(38) Wang, S.; Zhang, Z.; Liu, B. Catalytic Conversion of Fructose and 5-Hydroxymethylfurfural into 2,5-Furandicarboxylic Acid over a Recyclable $\mathrm{Fe}_{3} \mathrm{O}_{4}-\mathrm{CoO}_{\mathrm{x}}$ Magnetite Nanocatalyst. ACS Sustainable Chem. Eng. 2015, 3, 406-412.

(39) Yang, Z.; Qi, W.; Su, R.; He, Z. Selective Synthesis of 2,5Diformylfuran and 2,5-Furandicarboxylic Acid from 5-Hydroxymethylfurfural and Fructose Catalyzed by Magnetically Separable Catalysts. Energy Fuels 2017, 31, 533-541.

(40) Liu, L.; Chang, H.-m.; Jameel, H.; Park, J.-Y.; Park, S. Catalytic Conversion of Biomass Hydrolysate into 5-Hydroxymethylfurfural. Ind. Eng. Chem. Res. 2017, 56, 14447-14453.

(41) Wrigstedt, P.; Keskiväli, J.; Perea-Buceta, J.; Repo, T. J. OnePot Transformation of Carbohydrates into Valuable Furan Derivatives. Chem CatChem 2017, 9, 4244-4255.

(42) Motagamwala, A. H.; Won, W.; Sener, C.; Alonso, D. M.; Maravelias, C. T.; Dumesic, J. A. Toward biomass-derived renewable plastics: Production of 2, 5-furandicarboxylic acid from fructose. Sci. Adv. 2018, 4, No. eaap9722.

(43) Rathod, P. V.; Jadhav, V. H. Efficient Method for Synthesis of 2,5-Furandicarboxylic Acid from 5-Hydroxymethylfurfural and Fructose Using Pd/CC Catalyst under Aqueous Conditions. ACS Sustainable Chem. Eng. 2018, 6, 5766-5771.

(44) Chen, G.; Wu, L.; Fan, H.; Li, B.-g. Highly Efficient Two-Step Synthesis of 2,5-Furandicarboxylic Acid from Fructose without 5Hydroxymethylfurfural (HMF) Separation: In Situ Oxidation of HMF in Alkaline Aqueous $\mathrm{H}_{2} \mathrm{O} /$ DMSO Mixed Solvent under Mild Conditions. Ind. Eng. Chem. Res. 2018, 57, 16172-16181.

(45) Passerini, M.; Simone, L. Sopra gli isonitrili (I). Composto del p-isonitril-azobenzolo con acetone ed acido acetico. Gazz. Chim. Ital. 1921, 51, 126-129. 
(46) Ugi, I.; Steinbrückner, C. Isonitrile, II. Reaktion von isonitrilen mit carbonylverbindungen, aminen und stickstoffwasserstoffsäure. Chem. Ber. 1961, 94, 734-742.

(47) Ugi, I. The $\alpha$-addition of immonium ions and anions to isonitriles accompanied by secondary reactions. Angew. Chem., Int. Ed. 1962, 1, 8-21.

(48) Rudick, J. G. Innovative macromolecular syntheses via isocyanide multicomponent reactions. J. Polym. Sci., Part A: Polym. Chem. 2013, 51, 3985-3991.

(49) Kakuchi, R. Multicomponent reactions in polymer synthesis. Angew. Chem., Int. Ed. 2014, 53, 46-48.

(50) Llevot, A.; Boukis, A. C.; Oelmann, S.; Wetzel, K.; Meier, M. A. An update on isocyanide-based multicomponent reactions in polymer science. Top. Curr. Chem. 2017, 375, No. 66.

(51) Sehlinger, A.; Meier, M. A. R. Passerini and Ugi Multicomponent Reactions in Polymer Science. In Multi-Component and Sequential Reactions in Polymer Synthesis; Theato, P., Ed.; Advances in Polymer Science; Springer: Cham, 2014; Vol. 269.

(52) Yang, B.; Zhao, Y.; Wei, Y.; Fu, C.; Tao, L. The Ugi reaction in polymer chemistry: syntheses, applications and perspectives. Polym. Chem. 2015, 6, 8233-8239.

(53) Tunca, U. Click and multicomponent reactions work together for polymer chemistry. Macromol. Chem. Phys. 2018, 219, No. 1800163.

(54) Ugi, I. Polyamides from an Isonitrile, a Carboxylic Acid, an Amino and a Carbonyl Compound and a Process for Their Manufacture. US3277033A, 1963.

(55) Ugi, I.; von Bonin, W. Polyesteramide Prepared by Reacting a Carboxyl Containing Copolymer with an Isonitrile, and an Aldehyde or a Ketone. US3285992A, 1963.

(56) Kreye, O.; Tóth, T.; Meier, M. A. Introducing multicomponent reactions to polymer science: Passerini reactions of renewable monomers. J. Am. Chem. Soc. 2011, 133, 1790-1792.

(57) Robotham, C. V.; Baker, C.; Cuevas, B.; Abboud, K.; Wright, D. L. A multi-component reaction (MCR) approach to the synthesis of highly diverse polymers with polypeptide-like features. Mol. Diversity 2003, 6, 237-244.

(58) Kreye, O.; Türünç, O.; Sehlinger, A.; Rackwitz, J.; Meier, M. A. Structurally diverse polyamides obtained from monomers derived via the Ugi multicomponent reaction. Chem. - Eur. J. 2012, 18, 57675776.

(59) von Czapiewski, M.; Gugau, K.; Todorovic, L.; Meier, M. A. Synthesis of polyacrylates from limonene by catalytic oxidation and multi-component reaction. Eur. Polym. J. 2016, 83, 359-366.

(60) Sehlinger, A.; Ochsenreither, K.; Bartnick, N.; Meier, M. A. Potentially biocompatible polyacrylamides derived by the Ugi fourcomponent reaction. Eur. Polym. J. 2015, 65, 313-324.

(61) Yang, B.; Zhao, Y.; Wang, S.; Zhang, Y.; Fu, C.; Wei, Y.; Tao, L. Synthesis of multifunctional polymers through the Ugi reaction for protein conjugation. Macromolecules 2014, 47, 5607-5612.

(62) Sehlinger, A.; Bartnick, N.; Gunkel, I.; Meier, M. A.; Montero de Espinosa, L. Phase Segregation in Supramolecular Polymers Based on Telechelics Synthesized via Multicomponent Reactions. Macromol. Chem. Phys. 2017, 218, No. 1700302.

(63) Sehlinger, A.; Verbraeken, B.; Meier, M. A.; Hoogenboom, R. Versatile side chain modification via isocyanide-based multicomponent reactions: tuning the LCST of poly(2-oxazoline)s. Polym. Chem. 2015, 6, 3828-3836.

(64) Shen, H.; Ma, H.; Liu, P.; Huang, W.; Han, L.; Li, C.; Li, Y. Facile Synthesis of In-Chain, Multicomponent, Functionalized Polymers via Living Anionic Copolymerization through the Ugi Four-Component Reaction (Ugi-4CR). Macromol. Rapid Commun. 2017, 38, No. 1700353.

(65) Lucas, N.; Kanna, N. R.; Nagpure, A. S.; Kokate, G.; Chilukuri, $S$. Novel catalysts for valorization of biomass to value-added chemicals and fuels. J. Chem. Sci. 2014, 126, 403-413.

(66) Davis, S. E.; Zope, B. N.; Davis, R. J. On the mechanism of selective oxidation of 5-hydroxymethylfurfural to 2,5-furandicarbox- ylic acid over supported Pt and Au catalysts. Green Chem. 2012, 14, 143-147.

(67) Sehlinger, A.; Dannecker, P.-K.; Kreye, O.; Meier, M. A. Diversely substituted polyamides: macromolecular design using the Ugi four-component reaction. Macromolecules 2014, 47, 2774-2783.

(68) Wessjohann, L. A.; Rivera, D. G.; Vercillo, O. E. Multiple Multicomponent Macrocyclizations (MiBs): A Strategic Development Toward Macrocycle Diversity. Chem. Rev. 2009, 109, 796-814.

(69) Dannecker, P. K.; Sehlinger, A.; Meier, M. A. Polymacrocycles Derived via Ugi Multi-Component Reactions. Macromol. Rapid Commun. 2018, No. 1800748.

(70) Anastas, P.; Eghbali, N. Green Chemistry: Principles and Practice. Chem. Soc. Rev. 2010, 39, 301-312. 